Artigo recebido em 10/07/2015

Aprovado em 18/09/2015

Álvaro Nunes LaRangeira larangeira@terra.com.br Universidade Tuiuti do Paraná Coordenador do Programa de Pós-Graduação em Comunicação e Linguagens (PPGCOM-UTP) da Universidade Tuiuti do Paraná. Pós-doutor em Jornalismo pela Universidade de Coimbra e doutor em Comunicação pela PUCRS. Autor do livro A mídia e o regime militar (Sulina, 2014).
Estudos em Jornalismo e Mídia Vol. $12 \mathrm{~N}^{\circ} 2$ Julho a Dezembro de 2015, ISSN: $1984-6924$

\section{Silêncios permissivos: os cadernos especiais da Folha de S. Paulo e Jornal do Brasil no $10^{\circ}$ ano do regime militar}

\author{
Álvaro Nunes Larangeira
}

\begin{abstract}
Resumo
A partir do entendimento do silêncio como sujeito de um processo de conexão ideológica e percebendo a disposição/supressão morfológica do material jornalístico como elemento da camada macroproposicional do discurso, tem-se a tese de os silenciamentos ou redirecionamentos analíticos dos jornais Folha de S. Paulo e Jornal do Brasil nas edições do $10^{\circ}$ ano do regime militar, em 31 de março de 1974, expressarem a identificação do objeto de estudo, no caso a mídia, com o projeto da edificação de um regime político-econômico ideal, o qual seria proporcionado pela sociedade liberal capitalista, sendo aceitável, portanto, passar inclusive por governos/ditaduras militares para alcançar o fim último.
\end{abstract}

Palavras-chave

Silêncio permissivo, Imprensa, Mídia, Regime militar, Brasil.

\begin{abstract}
From the understanding of silence as the subject of an ideological connection process and realizing the layout / morphological suppression of journalistic material as part of macropropositional layer of discourse, there is the thesis of the silences or analytical redirects of the newspapers Folha de S. Paulo and Jornal do Brasil in the issues of $10 \mathrm{~h}$ years of military regime, on March 31, 1974, express the identification of the subject of study, in case the media, with the edification project of an ideal political-economic regime, which would be provided by the liberal capitalist society, being acceptable, therefore, spend including by government / military dictatorships to achieve the ultimate goal.
\end{abstract}

\section{Keywords}

Permissive silence, Press, Media, Military regime, Brazil. 
${ }^{1} 64 / 84$ : Autoritarismo e mudança. Jornal do Brasil, Rio de Janeiro, 1 abr. 1984, Caderno Especial, p. 1-6.

${ }^{2} O$ grande equívoco. Jornal do Brasil, Rio de Janeiro, $1 \mathrm{abr}$. 1984, Caderno Especial, p. 2.

${ }^{3}$ Tragédia social. Jornal do Brasil, Rio de Janeiro, 1 abr. 1984, Caderno Especial, p. 3.

${ }^{4}$ Um golpe, um crime. Jornal do Brasil, Rio de Janeiro, 1 abr. 1984, Caderno Especial, p. 3.

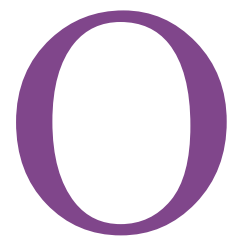

silêncio é ato indicial e propositivo por excelência. Nas efemérides dos 20 anos do regime militar, as publicações especiais da Folha de S. Paulo e Jornal do Brasil singram caminhos paralelos, para no final confluírem. As chamadas principais dos cadernos publicados na significativa data de $1^{\circ}$ de abril de 1984 complementamse na perspectiva analítica: "Jango e o golpe de 64" consta como título do primeiro artigo do suplemento da Folha de S. Paulo; "64/84: Autoritarismo e mudança" é a chamada do encarte do periódico carioca. Nos artigos e entrevistas aparecem as expressões "Golpe", "Golpe de 64", "Movimento golpista", "Regime autoritário", "Repressão". No Jornal do Brasil, há títulos como "O grande equívoco", "Tragédia social"3 e "Um golpe, um crime"4. O jornal paulista reserva praticamente toda a edição para, a partir da temática do governo Jango, traçar abordagens desabonadoras do regime militar.

Os dois suplementos alicerçamse na base consensual de o regime militar ser o resultado de um golpe de Estado protagonizado pelas Forças Armadas, com o respaldo dos segmentos da sociedade preocupados com a emergente mobilização e participação dos movimentos populares e sindicais na implementação do programa de reformas de base proposto pelo governo João Goulart. Apoiam o coup inconstitucional os latifundiários mobilizados pelas federações rurais estaduais e nacional; o empresariado comercial, industrial e financeiro representado pelo Conselho Nacional das Classes Produtoras (Conclap) e associado ao Instituto
Brasileiro de Ação Democrática (Ibad) e o Instituto de Pesquisas e Estudos Sociais (Ipes); entidades criadas especificamente para desestabilizar o governo federal e financiadas por empresas multinacionais e o governo norte-americano (por intermédio da Central de Inteligência Americana); setores da classe média descontentes com a política econômica reformista; e os protagonistas do "terrorismo semântico" anticomunista, mencionado no suplemento da Folha de S. Paulo. Aqui se constata o primeiro silêncio: a imprensa, eminente instância de intervenção sociopolítica desde o século 18, em nenhum momento é citada/esquadrinhada/inserida no contexto da época abordada.

Entre 1964 e 1974 são contabilizadas 4.841 pessoas punidas com perda dos direitos políticos, aposentadorias compulsórias, demissões. Foram cassados 513 parlamentares, entre senadores, deputados e vereadores. Trinta e cinco dirigentes sindicais são expurgados, 3.783 funcionários públicos perdem o emprego, tendo 72 professores universitários e 61 pesquisadores. Nas Forças Armadas, 43 generais, 240 coronéis, tenentes-coronéis e majores, 292 capitães e 708 suboficiais e sargentos são retirados das corporações; nas polícias civil e militar, 206 são afastados (FIGUEIREDO, 1978, p. 150151). No universo sindical, 483 sindicatos, 49 federações e quatro confederações sofrem intervenções. Mortes e assassinatos alcançam a casa da centena e 1.918 pessoas denunciam aos juízes militares torturas nas fases preliminares dos Inquéritos Policiais Militares (IPMs) (ARQUIDIOCESE, 2011, p. 98). E mesmo assim, com todo esse retrospecto, nos cadernos especiais da Folha de $S$. Paulo e Jornal do Brasil alusivos aos dez 
anos do regime militar, publicados no dia 31 de março de 1974 (e não no Dia dos Bobos), nenhuma referência a tais fatos aparece e, no plano semântico, imperam os termos "Revolução", "Revolução de 64", "Movimento de 31 de Março", "Modernização", "Democratização".

A partir do entendimento do silêncio como sujeito de um processo de conexão ideológica, e percebendo a disposição/ supressão morfológica do material jornalístico como elemento da camada macroproposicional do discurso, temse a tese de esses silenciamentos ou redirecionamentos analíticos, por parte dos dois jornais pesquisados, expressarem a identificação do objeto de estudo, no caso a mídia, com o projeto da edificação de um regime econômico ideal, o qual seria proporcionado pela sociedade liberal capitalista, sendo aceitável, portanto, passar inclusive por governos/ditaduras militares para alcançar o fim último. $\mathrm{O}$ artigo comporta o detalhamento dos sentidos do silêncio, a formação e as estratégias semânticas da informação, e a formulação da sociedade liberal capitalista modelar, à qual o Brasil necessitaria se moldar, ensejo iniciado nos anos 1950 por políticas norte-americanas como Doutrina Truman e Aliança para o Progresso, e ideia preponderante no Brasil na década de 1990, nas vigências dos governos Fernando Collor de Mello e Fernando Henrique Cardoso.

\section{O silêncio e suas políticas}

Por ser do conhecimento dos editores e articulistas dos suplementos e matérias especiais, os leitores do caderno especial do Jornal do Brasil e das oito páginas internas da Folha de S. Paulo sobre os dez anos do ciclo dos governos iniciados em abril de 1964 nada souberam da existência daqueles 4.841 brasileiros atingidos por banimentos, cassações, demissões, exílios e expurgos; das denúncias dos 1.918 cidadãos torturados nos IPMs, $81 \%$ dos quais no período 1969-1974; da pressão internacional por parte da Anistia Internacional, Comissão dos Direitos Humanos das Nações Unidas, Comissão Interamericana de Direitos Humanos, Comissão Internacional de Juristas e Conselho Mundial das Igrejas a partir das denúncias da Conferência Nacional dos Bispos do Brasil (CNBB) da execução e desaparecimento de corpos em centros de tortura; das operações de extermínio dos grupos guerrilheiros - Ação Libertadora Nacional (ALN), Movimento de Libertação Popular (Molipo), Partido Comunista Brasileiro Revolucionário (PCBR) e Partido Comunista do Brasil (PC do B), entre outros - dirigentes e militantes dos agrupamentos políticos proscritos pelos militares - como o Partido Comunista Brasileiro (PCB) - e da vigência do regime político amparado em 17 Atos Institucionais e respaldado por eleição indireta de um Congresso Nacional fantoche, depurado por cassações e fechado ou colocado em recesso conforme o estado de espírito da plutocracia militar.

A retirada intencional do objeto no enredo torna-se a prova inequívoca da existência do próprio objeto. A ausência é uma forma peculiar da presença ${ }^{5}$ e o silenciamento é a efetivação da materialidade do objeto desmaterializado sob a força das dissipações discursivas. Nesse sentido, o silêncio é o ato enunciativo da presentificação dos assuntos ablacionados pela forja do cenário idealizado e a representação negativada do ser existente. Em outubro
${ }^{5}$ A ausência é uma conexão de ser entre duas ou mais realidades humanas, conexão essa que necessita de uma presença fundamental dessas realidades umas às outras e, por outro lado, é somente uma das concretizações particulares desta presença. Estar ausente, para Pedro com relação a Teresa [exemplo dado pelo autor], é um modo particular de estar-lhe presente" (SARTRE, 2009, p. 357). 
de 2000, o contrato bilionário assinado entre a administração do democrata Bill Clinton e Israel para a venda à Força Aérea Israelense dos helicópteros de guerra Apache, na semana da rebelião nos territórios palestinos ocupados por forças israelenses, foi ignorado pela imprensa norte-americana, porque associaria o país aos massacres dos civis árabes. "A imprensa colaborou recusando-se a fazer qualquer comentário sobre o caso - vejam bem, não deixando de noticiar, mas recusando-se a fazê-lo; ela estava a par de tudo" (CHOMSKY, 2013, p. 101). Assim, pela deliberada mudez, reiteravase pela silenciosa denegação do irrefutável o perfilamento ideológico da mídia americana ao lado do aliado político, e a complacência com a política genocida empregada pelo parceiro comercial nos conflitos do Oriente Médio.

O silêncio também é o ornamentista do ato comunicacional desencadeado pelo suprimento temático, por exemplo, e em certos casos, o molde da significação. O silêncio, independente da fala ou da inexistência da expressão verbal, é, para Orlandi (2007), o significante:

Podemos mesmo chegar a uma proposição mais forte, invertendo a posição que nos é dada pelo senso comum (e sustentada pela ciência), na qual a linguagem aparece como "figura" e o silêncio como "fundo". Desse modo, podemos dizer que o silêncio é que é "figura", já que é fundante. Estruturante, pelo avesso. (ORLANDI, 2007, p. 31)

O autor canaliza essa concepção para a temática da censura no período da ditadura militar brasileira. O campo está assujeitado a dois tipos de esquecimentos do discurso apresentados por Pêcheux (2009): o esquecimento número 1 compreende a dominância da formação discursiva exterior (formulação da ilusória noção da intersubjetividade falante por parte do sujeito, visto ser ele o espelho do outro, reproduzindo o discurso alheio) sobre o sujeito-falante; e o esquecimento número 2 corresponde ao natural filtro empreendido pelo sujeito-falante no interior da formação discursiva à qual ele está subordinado (PÊCHEUX, 2009, p. 161-168).

Orlandi (2007) recorre a estudos de caso na música popular brasileira, na literatura e na imprensa para ilustrar a reação e resistência aos processos de produção de sentido pelas formas de interdição implementadas a partir de uma política de silêncio. Interessa-nos o caso relativo ao jornalismo. Os editores do Estado de $S$. Paulo e Jornal da Tarde, do mesmo grupo midiático, valeram-se do expediente da publicação de poemas e receitas culinárias para demarcar o espaço do material censurado pelo governo militar, metaforizando o recurso da resposta silenciosa ao silenciamento. Entretanto, temos no referido exemplo o silêncio silenciando uma das matrizes da política de silenciamento. Em 1961, a pedido dos chefes militares golpistas malsucedidos no impedimento da posse do vice-presidente João Goulart no lugar do renunciante Jânio Quadros, o dono do grupo Estado, Júlio de Mesquita Filho, elaborou ato institucional a ser publicado quando do êxito da destituição do presidente constitucional. Mesquita Filho redigiu o Ato Institucional do Governo Provisório da República dos Estados Unidos do Brasil, propondo 
uma junta militar no governo provisório por um ano e alternância anual das três armas no triênio seguinte, fechamento do Congresso, assembleias legislativas e câmaras municipais e tutela dos meios de comunicação. Em 13 de dezembro de 1968, a empresa sofreria a intervenção com base no Ato Institucional número 5 (AI-5) e o silenciador, ao ser vítima do silenciamento proposto por ele para aplicação a outrem, rebelar-se-ia.

\section{Os especiais da Folha de S. Paulo e} Jornal do Brasil dos dez anos do regime militar

Seria atitude prestidigitadora atribuir os silêncios explicitados nos caderno e material especiais da Folha de S. Paulo e Jornal do Brasil relativos ao décimo ano do regime militar as consequências do AI-5. As duas empresas haviam perfiladose ao regime decano desde a gênese do movimento. $\mathrm{O}$ editor, chefe de redação e comentarista político do Jornal do Brasil Wilson Figueiredo fazia parte do Grupo de Opinião Pública (GOP) do Ipes e, além do acompanhamento e divulgação das atividades ipesianas, colaborava na adaptação para a linguagem jornalística dos textos doutrinários e técnicos da entidade (DREIFUSS, 1981, p. 192234). O proprietário da empresa Jornal do Brasil, Nascimento Brito, criaria em 1963, com Roberto Marinho e João Calmon, representante dos Diários Associados, a Rede da Democracia, cujo propósito oficial era "defender e difundir as ideias democráticas e a Constituição do Brasil" e o objetivo real de desacreditar o governo João Goulart e dar voz à conspiração em andamento ${ }^{6}$. Durante a duração da rede 25 de outubro de 1963 a primeiro de abril de 1964 - apresentaram-se na estrutura midiática do trio - jornais e rádios $J B \mathrm{e}$ Globo, e as publicações e emissoras de rádio e TV do conglomerado Associados - todos os mentores e articuladores do movimento vitorioso em abril de 1964. No governo do general Emílio Garrastazu Médici, a empresa Jornal do Brasil seria contemplada com uma concessão de TV em Niterói, no Estado do Rio de Janeiro (BRASIL, 1973).

A empresa jornalística Folha da Manhã beneficiou-se do espólio resultante da perseguição e formatação do meio midiático posterior a 1964. Octavio Frias de Oliveira adquiriu em 1965 os jornais Última Hora paulista e Notícias Populares, e parte da TV Excelsior, por valores irrisórios. A UH foi obtida em negociação com o jornalista Samuel Wainer, exilado em Paris depois da perda dos direitos políticos pelo Ato Institucional número 1 , editado na segunda semana do golpe. O NP foi praticamente repassado a Frias de Oliveira, porque para o antigo proprietário, o deputado federal pela União Democrática Nacional (UDN) e empresário ipesiano Herbert Levy, perdera sentido manter o jornal popular fundado em 1963 para fazer frente ao Última Hora na capital paulista. Sendo concessão federal, a apropriação da $T V$ Excelsior necessitou do aval do chefe da Casa Militar no governo Castello Branco, o general Ernesto Geisel. A empatia do proprietário da Folha de S. Paulo com segmentos militares foi a causa da ameaça de morte endereçada a ele em 1971 pela ALN e a Vanguarda Popular Revolucionária(VPR), acusando-o de ceder veículos da empresa aos órgãos de repressão nas campanas e prisões de guerrilheiros (PASCHOAL, 2007, p. 157-158; p. 134-137). A Folha de S. Paulo foi o único entre os quatro
${ }^{6}$ No ar a partir de hoje a Cadeia da Democracia, com rádios JB, Globo e Tupi, Jornal do Brasil, 25 out. 1963, p. 3; CARVALHO, 2010, $p$. 15. 
${ }^{7}$ Os outros três eram:

Estado de S. Paulo, o

Jornal do Brasil e $O$ Globo.

${ }^{8}$ Caso Herzog: divulgado relatório do IPM, Folha de S. Paulo, $1^{\circ}$ caderno, p. 4 e 5, 20 dez. 1975.

${ }^{9}$ Movimento de abril a abril: cassações, prisões e asilos, Correio da Manhã, 1 abr. 1965,

2. Caderno, p. 1

${ }^{10}$ Um ano: saldo favorável. Folha de S.

Paulo, São Paulo, 31 mar. 1965 , 1. caderno,

11 "Uma função que cruza um domínio de estruturas e de unidades possiveis e que faz com que apareçam, com conteúdos concretos, no tempo e no espaço" (FOUCAULT, 1997, p.

99).

${ }^{12}$ Folha de S. Paulo,

31 mar. 1974, 2. caderno, p. 15, 22 e 24 ,

respectivamente. principais diários do país na época ${ }^{7}$ a publicar ipsis litteris o fantasioso relatório do II Exército sobre a morte do jornalista Vladimir Herzog nas dependências em São Paulo do Destacamento de Operações de Informações do Centro de Operações de Defesa Interna (DOI-CODI), sem interpelar a versão do suicídio ${ }^{8}$.

Se o primeiro ano dos militares no poder havia sido considerado pela Folha de $S$. Paulo benéfico para o país - mesmo com 15 mil pessoas detidas, 40 mil indiciados em IPMs federais e estaduais, 10 mil demissões e aposentadorias forçadas, mil intervenções em confederações, federações e sindicatos, 500 asilados e 378 brasileiros cassados $^{9}$-, expressando o contentamento no editorial "Um ano: saldo favorável"10, publicado em 31 de março de 1965, na data dos dez anos do regime militar a avaliação do jornal aproximou-se do apoteótico. Em oito páginas diluídas na edição de 31 de março de 1974, as sete chamadas dos textos e os 14 artigos e reportagens enaltecem as políticas do regime nas áreas política, econômica, social, cultural, educacional e na saúde. Proliferam-se nos textos a positividade do período por meio do desmembramento dos termos-chave, aqui considerados como enunciados na acepção adotada por Foucault ${ }^{11}$, central no contexto: "Revolução" e "Movimento de 64". Em um único artigo, "Decisões políticas do presidente Castello Branco", escrito pelo chefe da Casa Civil da Presidência da República no governo citado, a palavra "Revolução", na forma substantivada, aparece 13 vezes, próximo a um terço do total das 34 menções em toda a edição.

No cotejamento (Tabela 1) das publicações do décimo ano pela Folha de S. Paulo e Jornal do Brasil temos desproporcionalidades, similitudes e peculiaridades. Em espaço comparativo próximo - oito e seis páginas - a Folha tem três vezes e meio mais cartolas e matérias em relação ao Jornal do Brasil (21 a seis) e o dobro dos termos-chave indicativos da simpatia do avaliador com o objeto analisado (17 a oito). Sintonizam os dois nas proposições ideológicas idênticas representadas pelos titulamentos, chamadas, palavras, expressões e enfoques, todos eles elogiosos ao regime militar. As particularidades extraídas da comparação são extensões corroborativas da predisposição identitária das publicações. O material do Jornal do Brasil foi compilado no formato de caderno especial, enfatizando o princípio pedagógico do produto, e a Folha de S. Paulo inovou na finalidade das cartolas - geralmente chamativas apenas para o assunto -, fazendo das mesmas sentenças completas, como em "O que se fez nos últimos 10 anos garante o futuro", "Escolarização aumentou 30\% na faixa 7/14 anos" e "No ensino superior, matrículas cresceram 300\%" 
1974 - dez anos do regime militar

Folha de S. Paulo - oito páginas intemas: quatro no $1^{\circ}$ cademo e quatro no $2^{\circ}$ cademo.
Jornal do Brasil - Cademo especial - seis páginas

Cartolas e matérias

\begin{tabular}{|c|c|c|c|}
\hline Elogiosas ao regime militar & $\begin{array}{|ll|}\begin{array}{l}\text { Críticas ao } \\
\text { militar }\end{array} & \\
\end{array}$ & $\begin{array}{|lll|}\begin{array}{l}\text { Elogiosas ao } \\
\text { militar }\end{array} & & \text { regime } \\
\end{array}$ & $\begin{array}{l}\text { Críticas ao regime } \\
\text { militar }\end{array}$ \\
\hline $\begin{array}{l}\text { Cartolas: } \\
\text { Os idos de março; } \\
\text { O preço da impopularidade; } \\
\text { O esboço do modelo de } \\
\text { desenvolvimento; } \\
\text { O que se fez nos últimos } 10 \\
\text { anos garante o futuro; } \\
\text { Escolarização aumentou } 30 \% \\
\text { na faixa } 7 / 14 \text { anos; } \\
\text { As formas supletivas de } \\
\text { ensino e telecomunicações; } \\
\text { No ensino superior, } \\
\text { matriculas cresceram } 300 \% \text {. } \\
\text { Matérias: } \\
\text { A conspiração em poucos } \\
\text { dias; } \\
\text { Decisões políticas } \\
\text { Presidente Castelo Branco; } \\
\text { O movimento tinha raizes } \\
\text { profundas; } \\
\text { O que deveria ser e o que foi; } \\
\text { Costa e Silva quis retomar o } \\
\text { diálogo; } \\
\text { O acerto com que agimos em } \\
64 \text {; } \\
\text { Toma forma o Milagre } \\
\text { Brasileiro": } \\
\text { Ordens do Dia: destacam os } \\
\text { valores da nacionalidade; } \\
\text { A Revolução, segundo Laudo } \\
\text { Natel; } \\
\text { Melhores dias para a saúde do } \\
\text { brasileiro; } \\
\text { MEC apresenta seu balanço; } \\
\text { Na educação, dez anos } \\
\text { significativos; } \\
\text { Erradicar o analfabetismo, } \\
\text { velho ideal; } \\
\text { Os caminhos invios da } \\
\text { educação nacional. }\end{array}$ & & $\begin{array}{l}\text { A doutrina revolucionária } \\
\text { em evolução; } \\
\text { A Revolução dez anos } \\
\text { depois; } \\
\text { O Salto econômico; } \\
\text { As obras do país; } \\
\text { As grandes decisões de } \\
\text { Castelo; } \\
\text { Chile: em busca do } \\
\text { tempo perdido. }\end{array}$ & \\
\hline Total: 21 & Total: 0 & Total: seis & Total: 0 \\
\hline
\end{tabular}


Termos-chave nos textos

\begin{tabular}{|c|c|c|c|}
\hline Elogiosos ao regime militar & $\begin{array}{l}\text { Críticos ao regime } \\
\text { militar }\end{array}$ & $\begin{array}{l}\text { Elogiosos ao regime } \\
\text { militar }\end{array}$ & $\begin{array}{l}\text { Críticos ao regime } \\
\text { militar }\end{array}$ \\
\hline $\begin{array}{l}\text { Brasil novo; } \\
\text { Espirito revolucionário; } \\
\text { Governo revolucionário; } \\
\text { Idos de março; } \\
\text { Milagre econômico; } \\
\text { Movimento de } 64 ; \\
\text { Movimento de } 31 \text { de Março; } \\
\text { Movimento de } 31 \text { de Março } \\
\text { de } 1964 ; \\
\text { Ordem revolucionária; } \\
\text { Poder militar; } \\
\text { Preceitos revolucionários; } \\
\text { Processo revolucionário; } \\
\text { Reconstrução; } \\
\text { Revolução } \\
\text { Revolução de 64; } \\
\text { Revolução de Março de } 64 ; \\
\text { Sistema revolucionário }\end{array}$ & & $\begin{array}{l}\text { Conspiração defensiva; } \\
\text { Forças subversivas; } \\
\text { Governo revolucionário; } \\
\text { Grupos subversivos; } \\
\text { Periodo revolucionário; } \\
\text { Processo revolucionário; } \\
\text { República sindicalista; } \\
\text { Revolução de } 64\end{array}$ & \\
\hline Total: 17 & Total: 0 & Total: oito & Total: 0 \\
\hline
\end{tabular}

Tabela 1: quadro da produção jornalística da Folha de S. Paulo e Jornal do Brasil para a efeméride dos dez anos do regime militar. Fontes: Folha de S. Paulo e Jornal do Brasil (31 de março de 1974).

O alinhamento midiático à visão da Paulo, 2010). Os três últimos governos sociedade liberal modelar correspondem aos mandatos de Fernando

Duas assertivas do Projeto Folha, Collor de Mello (1990-1992), Itamar da versão de 1997, indicam a razão do Franco (1992-1994) e Fernando Henrique alinhamento da imprensa convencional com o regime militar em 1974: "Os meios de comunicação têm assegurado grande visibilidade para a linha de reformas liberalizantes observada nos três últimos governos. Ao fazê-lo, refletem uma tendência internacional que recebe apoio crescente na opinião pública interna" e "A necessidade de adaptação nacional à dinâmica externa, imperativo aguçado na época que atravessamos, atualiza os problemas tradicionais em que a divisão entre um setor integrado e um setor Cardoso (1995-2002), e representaram a efetiva inserção brasileira nos processos da globalização econômica neoliberal, hegemônica no plano conceitual desde o solapamento, em 1991, do país-base do contraponto à visão capitalista norteamericana, a União das Repúblicas Socialistas Soviéticas(URSS). Jáa segunda premissa, da adequação interna ao cenário internacional (entenda-se economia de mercado nos moldes imperialistas), era um dos postulados do programa Aliança para excluído nada tem de novo" (Folha de S. John Kennedy para disponibilizar recursos 
financeiros e auxílio técnico a países latino-americanos. Em tese, o objetivo do programa era "propiciar vida melhor a todos os habitantes do continente" ${ }^{13}$, e, na realidade, financiar grupos anticomunistas e conservadores opositores a governos com tendências esquerdistas, como considerava o Departamento de Estado norte-americano o caso do Brasil.

A tiragem de um milhão do encarte Cartilha para o Progresso - como se faz uma revolução sem sangue, com as propostas do programa e publicado em 1962 nos principais jornais paulistas e cariocas, foi financiada pelo Ipes, e a última página da publicação, intitulada "Uma advertência", sintetizava a perspectiva do instituto:

É nossa convicção que, se levada à plena realidade, a Aliança para o Progresso proporcionará à América Latina em geral e, ao Brasil, em particular, uma nova era em que a democracia política e a liberdade serão definitivamente consolidadas pela extensão dos ideais democráticos, ao campo do econômico e do social ${ }^{14}$.

A concepção de democracia do instituto - posteriormente incorporada pelo regime militar e os meios de comunicação, entre eles a Folha de S. Paulo e o Jornal do Brasil - refutava a participação dos segmentos populares e movimentos sociais - por associá-los ao comunismo - e pactuava com governos autoritários intermediários da sociedade democrática pretendida. Seria essa a mensagem subtendida no título do caderno especial do Jornal do Brasil, "A doutrina revolucionária em evolução", e no último parágrafo do editorial da Folha de S. Paulo - "Eis uma das conquistas básicas da doutrina estabelecida há 10 anos. Através dela, o Brasil faz do projeto da construção nacional um exercício permanente de reciclagem do modelo, reduzindo sua margem de erro e elevando o seu padrão de eficiência. E acima de tudo, o Brasil já desfruta da confortável situação de conhecer os caminhos que deve evitar e os caminhos que pode trilhar"15-, nas edições de 31 de março de 1974, justificando silenciamentos estratégicos?

\section{Referências}

ARQUIDIOCESE de São Paulo. Brasil: nunca mais. Petrópolis: Vozes, 2011.

BRASIL. Congresso. Senado. Decreto $n^{\circ} 72567$, de 01 de agosto de 1973 . Decreto $\mathbf{N}^{\mathbf{0}}$ 72.567, de 1 de Agosto de 1973. Disponível em: <http://legis.senado.gov.br/legislacao/ ListaTextoIntegral.action?id=186462\&norma=202131.>. Acesso em: 19 nov. 2015.

CHOMSKY, Noam. Mídia: propaganda política e manipulação. São Paulo: Martins Fontes, 2013.

DREIFUSS, René Armand. 1964: A conquista do Estado: ação política, poder e golpe de classe. 2. ed. Petrópolis: Vozes, 1981. 
FIGUEIREDO, Marcus Faria. A política de coação no Brasil pós-64. In:

FIGUEIREDO, Marcus; KLEIN, Lúcia. Legitimidade e Coação no Brasil pós-64. Rio de Janeiro: Forense-Universitária, 1978.

FOLHA DE S. PAULO. Manual de redação. 14. ed. São Paulo: Publifolha, 2010.

FOUCAULT, Michel. A arqueologia do saber. 5. ed. Rio de Janeiro: Forense Universitária, 1997.

ORLANDI, Eni Puccinelli. As formas do silêncio: no movimento dos sentidos. 6. ed. Campinas: Unicamp, 2007.

PASCHOAL, Engel. A trajetória de Octavio Frias de Oliveira. São Paulo: Publifolha, 2007.

PÊCHEUX, Michel. Semântica e discurso: uma crítica à afirmação do óbvio. Campinas: Unicamp, 2009.

SARTRE, Jean-Paul. O ser e o nada: ensaio de ontologia fenomenológica. Petrópolis: Vozes, 2009.

Estudos em Jornalismo e Mídia está sob a licença Creative Commons 2.5 